\title{
Highly Efficient Chelating Polymers Based on Plastic Waste for Removal of Toxic Heavy Metal Pollutants
}

\author{
Rasha Abdel Baseer, A. B. Mostafa, A. Rabei* and Noha \\ Elhalawany $^{\#}$ \\ Polymers and Pigments Department, National Research Centre \\ and *hemistry Dept., Ain Shams University, Cairo, Egypt.
}

\begin{abstract}
W EW efficient chelating polymers CPs based on waste poly(methylmethacrylate) (PMMA) functionalized by itaconic acid moieties in absence and presence of montmorillonite clay MMT have been prepared by simple solution polymerization technique. The obtained CPs have been characterized using various techniques such as Fourier-Infra-red (FT-IR), scanning electron microscope (SEM), differential scanning calorimetric (DSC) and thermo gravimetrical analysis (TGA). The prepared CPs has been used as potential adsorbents for removal of different toxic metal ions from their aqueous solutions. The CP containing MMT clay showed higher sorption capacity. The adsorption performance of the prepared CPs has been found to match well with Langmuir adsorption isotherms. The maximum sorption capacity for $\mathrm{Cu}^{+2}$ ions was found to be $200.7 \mathrm{mg} / \mathrm{g}$ at natural $\mathrm{pH} 5.8$ and was highly enhanced to reach $478.6 \mathrm{mg} / \mathrm{g}$ at higher $\mathrm{pH}$ values. The correlation coefficient values showed that the sorption of $\mathrm{Cu}^{+2}$ ions by $\mathrm{CP}$ with and without clay fit well pseudosecond order models. The highest sorption affinity of the prepared CPs towards different metal ions was in the order $\mathrm{Co}>\mathrm{Ni}>\mathrm{Pb}>\mathrm{Cu}>\mathrm{Cd}>$ $\mathrm{Cr}$ and $\mathrm{Pb}>\mathrm{Cu}>\mathrm{Cd}>\mathrm{Ni}>\mathrm{Co}>\mathrm{Cr}$ for $\mathrm{CP}$ without and with clay respectively.
\end{abstract}

Keywords: Chelating polymers, Copper ion uptake, Sorption kinetics, and Sorption affinity.

Nowadays heavy metal pollution has come to be one of the most serious threats for environment. Exposure to a trace of heavy metals is considered a risk for human beings ${ }^{(1-4)}$. Thus, how to efficiently and extremely get rid of toxic heavy metals from water systems is still a very important but still interesting task for environmental engineers. Many technologies such as chemical precipitation, ion exchange, adsorption, membrane filtration have been adopted to remove poisonous metal ions from water ${ }^{(5-9)}$. Recently, numerous approaches have been discovered to develop low-priced and more effective technologies for water purification. Adsorption has proven to be cost-effective and competent for removing heavy metals, organic pollutants and dyes from water systems ${ }^{(10)}$. Adsorbents attracted vast attention due to accessibility of various adsorbent

${ }^{\#}$ Corresponding author:

Email: nr.ibrahim@nrc.sci.eg - elhalawany1933@gmail.com 
types, environmental friendly, cost viability, and their high effectiveness in removal of organic and inorganic pollutants. There are several important standards governing the selection and design adsorbents such as fast removal, ion selectivity and reusability ${ }^{(11,12)}$

Recently, adsorbents built on nanomaterials gained great attention due to their extraordinary performance to adsorb pollutants from aqueous environments such as carbon nanotubes, titania, silica and clay polymer composites ${ }^{(13-17)}$. Ionic polymer clay nanocomposites ${ }^{(18)}$ showed effectiveness for removal of inorganic and organic pollutants ${ }^{(19,20)}$. The sorption capacity of polymer-clay composites was affected by preparation process, type of polymer-clay composites and application technique such as membrane, nano-filters, etc ${ }^{(21-23)}$.

The use of (inorganic-organic) nanomaterials such as polymer clay composites as an adsorbent is regarded as one of the most effective methods for removal of heavy metal ions from aqueous phase ${ }^{(24)}$. On other hand, structural flexibility, mechanical performance and prospective applications in harsh environmental conditions are some of the major merits of these hybrid polymeric materials. Research is working on synthesizing and testing the possibilities to apply these hybrid polymeric adsorbents for removal of toxic metal ions from aqueous solutions ${ }^{(25-29)}$.

Considering the merits of the aforementioned polymer- clay composites as adsorbents, in present study, we have synthesized new efficient, low-cost chelating polymers CPs based on cheap waste polymeric materials for efficient removal of some toxic heavy metal ions from their aqueous solutions.

Materials

\section{Experimental}

Copper acetate $\left(\mathrm{CH}_{3} \mathrm{COO}\right)_{2} \mathrm{Cu} .4 \mathrm{H}_{2} \mathrm{O}$, cobalt acetate $\mathrm{Co}(\mathrm{Ac})_{2} \cdot 4 \mathrm{H}_{2} \mathrm{O}$, nickel acetate $\mathrm{Ni}(\mathrm{Ac})_{2} \cdot 4 \mathrm{H}_{2} \mathrm{O}, \mathrm{CrCl}_{3} \cdot 6 \mathrm{H}_{2} \mathrm{O}$, cadmium acetate $\mathrm{Cd}(\mathrm{Ac})_{2} \cdot 2 \mathrm{H}_{2} \mathrm{O}$, lead acetate $\mathrm{Pb}(\mathrm{Ac})_{2} \cdot \mathrm{OH}, \mathrm{Cu}(\mathrm{Ac})_{2} \cdot \mathrm{H}_{2} \mathrm{O}$, butyl acrylate $\mathrm{BA}$ and itaconic acid IA are products of Sigma Aldrich, Saint Louis, Missouri, USA. All other chemicals used were chemically pure and are products of Prolabo Chemical Company (BDH, England).

\section{Characterization techniques}

Infra-red spectra IR

IR analyses of the prepared CPs have been measured using Jasco 6100 plus FT-IR spectrometer, Japan.

Differential scanning calorimetric analysis (DSC) and thermo-gravimetric analysis (TGA)

Thermal analyses TGA and DSC for the tested samples have been measured using a Perkin Elmer, thermogravimetric analyzer, USA, under nitrogen conditions. The heating rate was $10^{\circ} \mathrm{C}$ per minute from $50^{\circ} \mathrm{C}$ to $500^{\circ} \mathrm{C}$.

Egypt. J. Chem. 59, No. 2 (2016) 
Scanning electron microscope/energy dispersion X-ray (SEM/EDX)

Morphological studies as well as element constitution of the tested samples have been measured using SEM /EDX (JEOL JXA- 840 A Electron PROBE), microanalyzer microscope, Japan.

UV-VIS spectrophotometer

Spectrophotometric measurements were carried out using UV-vis (JASCO V630) spectrophotometer, Japan.

\section{Synthesis of chelating polymers CPS}

In presence of MMT clay

The synthesis reaction was done according to previous work by Elhalawany et al. ${ }^{(21)}$ and it is in detail as follows: First, 6g WPMMA and $0.2 \mathrm{~g}$ MMT were soaked in $25 \mathrm{ml}$ dioxane and then homogenized using Greaves homogenizer $\mathrm{X} 120$, Germany at $6000 \mathrm{rpm}$ for $10 \mathrm{~min}$. The previous homogenized solution was charged into $100 \mathrm{ml}$ two-neck flask fitted with a reflux condenser followed by the addition of $0.2 \mathrm{~g}$ benzoyl peroxide PBO dissolved in $5 \mathrm{ml}$ dioxane and $(9.6 \mathrm{x}$ 10-3) moles BA dropwisely under continuous stirring at $750 \mathrm{rpm}$ at $75^{\circ} \mathrm{C}$. The reaction was left for $2 \mathrm{hr}$ to form the seed polymer. Finally a (3.8x10-3) mole of IA was added to the reaction media. The polymerization reaction was left for further $2 \mathrm{hr}$. The resultants CP have been purified by washing with water / methanol mixture of ratio $(3: 1)$ several times to remove the unreacted water soluble monomers followed by soxhlet extraction from diethyl ether to remove the excess initiator and the unreacted BA monomer.

In absence of clay

The reaction was done as the aforementioned procedure.

Determination of equilibrium swelling values (ESVs) of CPs

A known amount of dry polymer was immersed in distilled water at room temperature and held there at different times, and then weighed. The ESV of the CPs was determined gravimetrically by using the following equation:

$$
\mathrm{ESV}\left(\mathrm{gH}_{2} \mathrm{O} / \mathrm{g}_{\mathrm{CP}}\right)=\left(\mathrm{w}_{\mathrm{s}}-\mathrm{w}_{\mathrm{d}}\right) / \mathrm{w}_{\mathrm{d}} \quad \mathrm{Eq}(1)
$$

where $\mathrm{w}_{\mathrm{s}}$ and $\mathrm{w}_{\mathrm{d}}$ are the weights of swollen and dry CPs, respectively.

\section{Metal ion uptake measurements}

Preparation of $\mathrm{Cu}(\mathrm{II})$ solution

Stock solution of copper ion of initial concentration $C_{i}\left(7.852 \times 10^{3} \mathrm{mg} / \mathrm{L}\right)$ has been prepared by dissolving $1.963 \times 10^{3} \mathrm{mg}$ copper acetate in $250 \mathrm{ml}$ distilled water.

\section{Copper ion uptake experiments}

A $0.3 \mathrm{~g}$ of the obtained CPs was placed into separating funnel with sintered glass filter system containing $30 \mathrm{ml}$ of copper acetate solution of well-known initial concentration $\left(\mathrm{C}_{\mathrm{i}}\right)$ at room temperature for a definite time. The residual concentration $\left(\mathrm{C}_{\mathrm{r}}\right)$ of the copper ion under investigation was determined using UV-Visible (UV-vis) 
spectrophotometer via different absorption/concentration standard curves. The copper ion uptake (CIU) was determined according to Equation 2:

$$
\mathrm{q}_{\mathrm{e}}=\mathrm{V}\left(\mathrm{C}_{\mathrm{i}}-\mathrm{C}_{\mathrm{r}}\right) / \mathrm{m} \quad \mathrm{Eq}(2)
$$

where $C_{i}$ and $C_{r}$ are the initial and final metal ion concentration (mg/L), respectively, $\mathrm{V}$ is the volume of solution $(\mathrm{L})$ and $\mathrm{m}$ is the mass of the dried CPs $(\mathrm{g})$.

Effect of $\mathrm{pH}$ on the uptake of copper ion

Uptake experiments under controlled $\mathrm{pH}$ were carried out following the above procedure for uptake experiments. The $\mathrm{pH}$ was adjusted using the suitable buffer.

Competitive removal of metal ions from aqueous solution

A mixture solution containing $\left(\mathrm{Cr}^{+3}, \mathrm{Co}^{+2}, \mathrm{Ni}^{+2}, \mathrm{Cu}^{+2}, \mathrm{Cd}^{+2}, \mathrm{~Pb}^{+2}\right)$ ions of concentrations $(1281,1057,1051,197.5,592.7,331.4) \mathrm{mg} / \mathrm{L}$ respectively was added to $0.05 \mathrm{~g}$ of dry $\mathrm{CP}$ at room temperature and left for two hours. The percentage of adsorbate ions onto the $\mathrm{CP}$ was determined by EDAX (JEOL JXA840 A Electron PROBE) microanalyzer microscope.

\section{Results and Discussion}

The resultant $\mathrm{CP}$ in presence of MMT is supposed to have the following conceptual structure and it is represented in Fig.1.

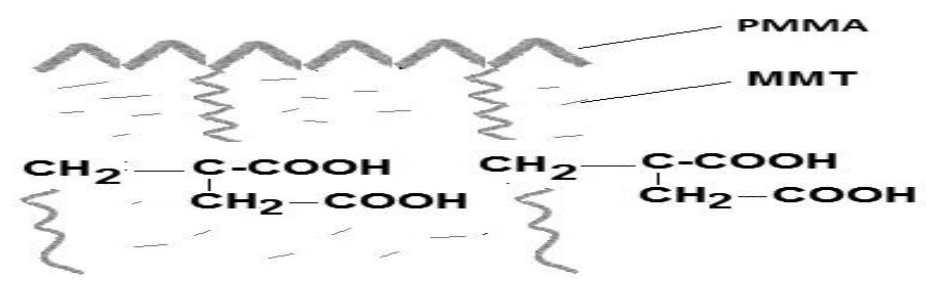

Fig.1. Conceptual structure of the prepared CP in presence of MMT clay.

The proposed mechanism for the interaction of the prepared CPs with the studied copper ions is illustrated in Fig. 2.
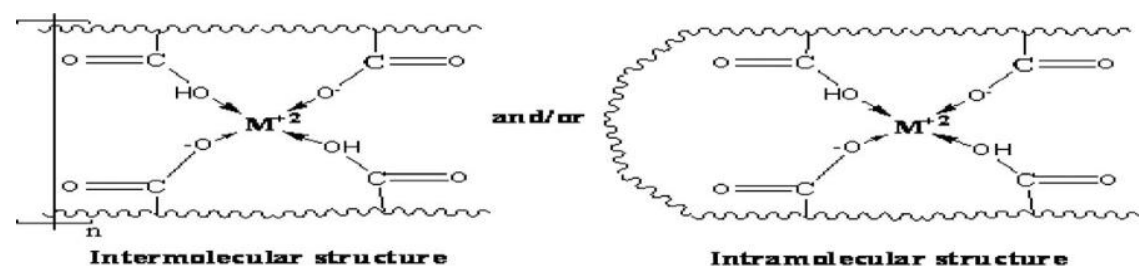

$M=C u(I I)$

Intramal ecular structure

Fig. 2. The interaction of the prepared CPs with the tested copper ion.

Egypt. J. Chem. 59, No. 2 (2016) 


\section{Characterization of the prepared CPs}

\section{FT-IR spectra}

The FT-IR spectra of CPs with and without clay are represented in Fig. 3. The adsorption bands at $3438,1452 \mathrm{~cm}^{-1}$ are attributed to the stretching and bending of O-H group of IA. The adsorption bands at 1732 and $1156 \mathrm{~cm}^{-1}$ are attributed to $\mathrm{C}=\mathrm{O}$ and $\mathrm{C}-\mathrm{O}$ stretching of ester group of BA and PMMA. The adsorption band at 1159 is attributed to $-\mathrm{O}-\mathrm{CH}_{3}$ stretching vibrations ${ }^{(30)}$.

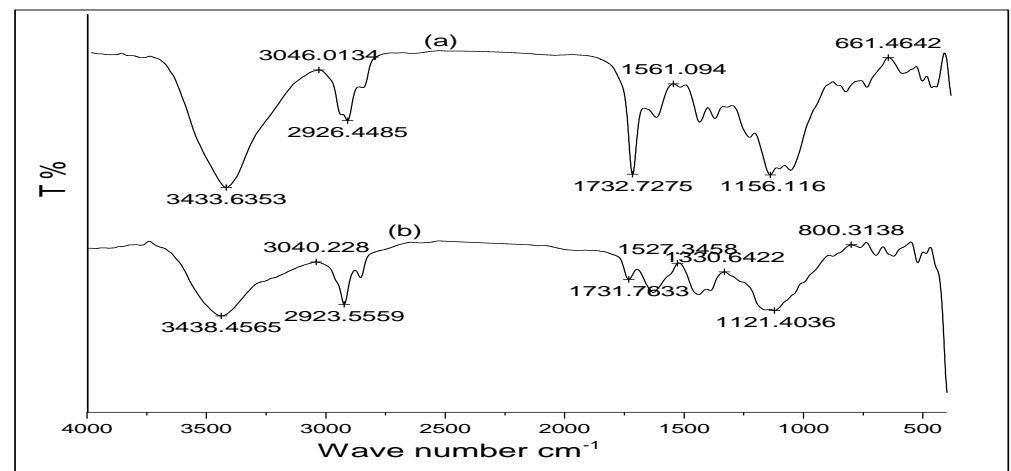

Fig. 3. FT-IR spectra of the prepared CPs a) without clay and B) with clay.

Thermo-gravimetric analysis (TGA)

Thermo gravimetric analyses for the prepared CPs are shown in Fig. 4. It is clearly seen from the figure that there are two major stages of weight loss for grafted PMMA with IA; where in the first stage the weight losses of CP with and without clay are $30.88 \%$ and $26.5 \%$ at temperatures $363.01^{\circ} \mathrm{C}$ and $337.35^{\circ} \mathrm{C}$, respectively. On the other hand the weight loses of $\mathrm{CP}$ with and without clay in the second stage is $57.96 \%$ and $66.48 \%$ at temperatures $399.42^{\circ} \mathrm{C}$ and $372.69^{\circ} \mathrm{C}$. The $\mathrm{CP}$ containing clay showed higher thermal stability. In general, it can be concluded that the presence of slight amount of MMT clay enhances the thermal stability.

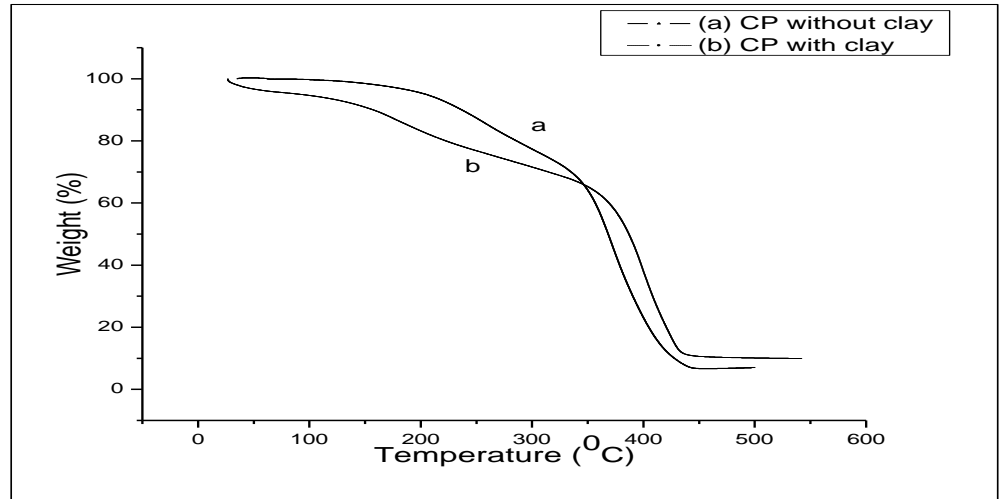

Fig. 4. TGA of the prepared CPs (a) without clay and (b) with clay. 
Differential scanning calorimetry (DSC)

Figure 5 shows DSC thermograms of the prepared CPs in absence and presence of MMT clay. The glass transitions temperature (Tg) appear at 75.50 and $168.91^{\circ} \mathrm{C}$ for $\mathrm{CP}$ without and with clay, respectively. In addition, the endothermic melting transitions for $\mathrm{CP}$ without and with clay appear at 75.50 and $168.91^{\circ} \mathrm{C}$, respectively.

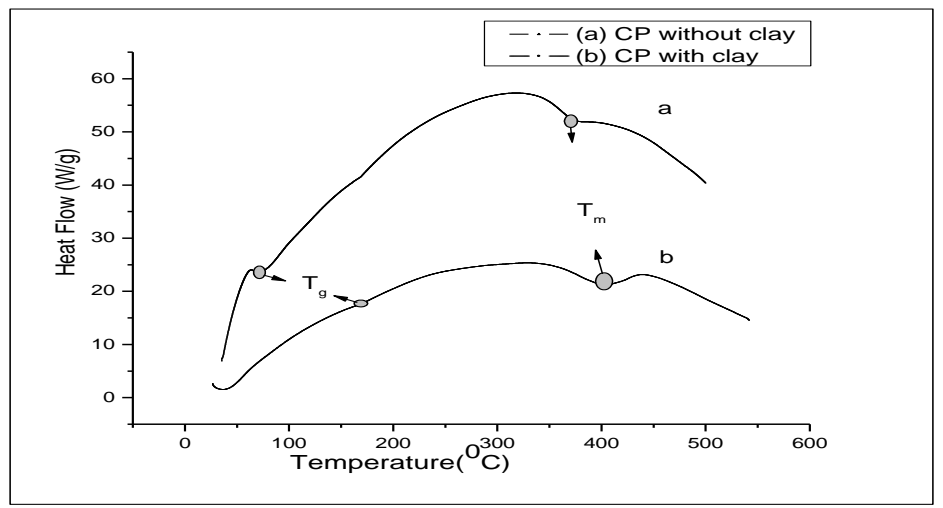

Fig. 5. DSC curves for the prepared CPs (a) without clay and (b) with clay.

\section{Scanning electron microscope (SEM)}

Scanning electron microscope (SEM) analysis for the prepared CPs in presence and absence of MMT clay is shown in Fig. 6. Figure 6 showed that the $\mathrm{CP}$ without MMT showed that the $\mathrm{CP}$ with MMT is more porous than that without clay which increases the efficiency of metal ion removal indicating well dispersed MMT nanoparticles through the polymer matrix and this morphological situation is believed to be responsible for enhanced sorption capacity.

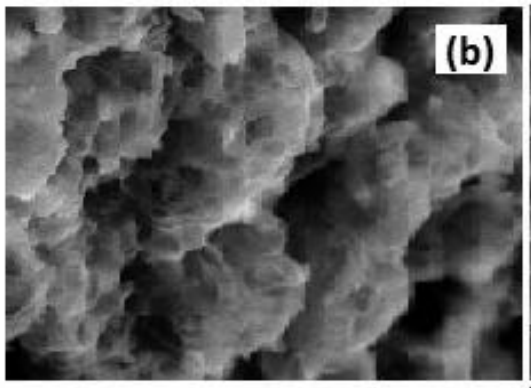

$50 \mu \mathrm{m}$ $1000 x$

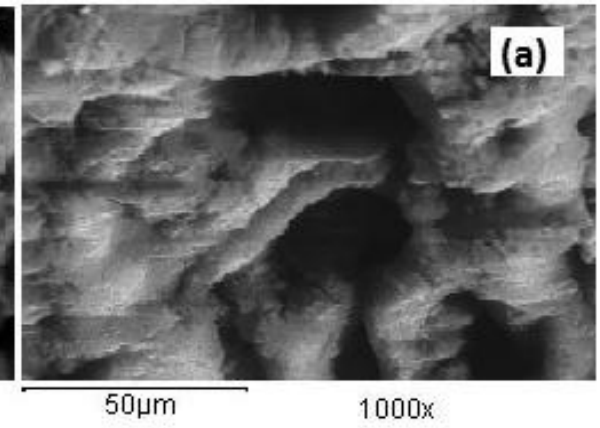

Fig. 6. SEM for the surface morphology of CPs (a) without clay and (b) with clay.

\section{Equilibrium swelling values (ESVs) of CPs}

Equilibrium swelling values (ESVs) by the prepared CPs at different time intervals is shown in Fig. 7. It is clearly seen from the figure that the equilibrium swelling values (ESVs) of CPs by the prepared CPs are fixed in the rise and fall sequentially.

Egypt. J. Chem. 59, No. 2 (2016) 


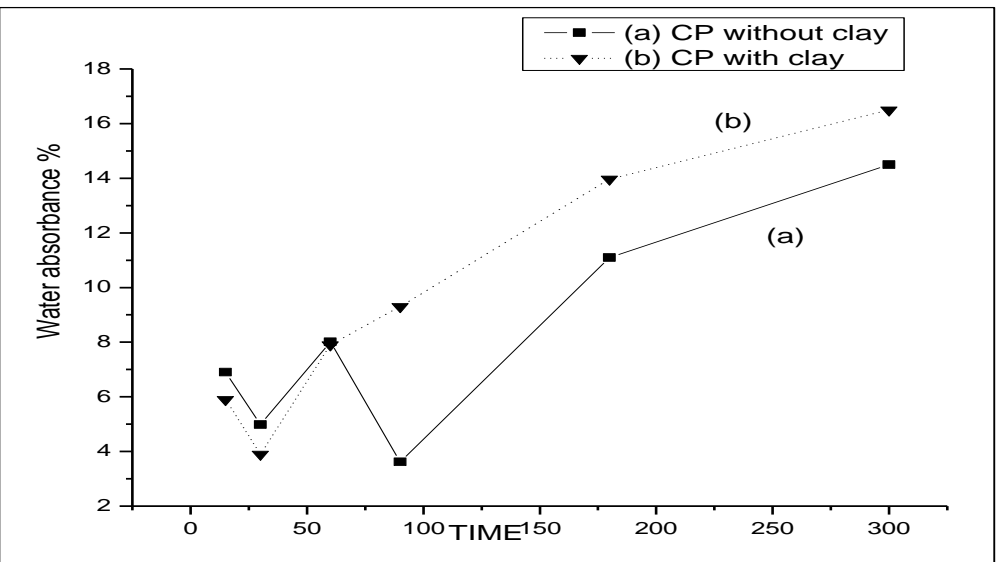

Fig. 7. Equilibrium swelling values (ESVs) by the prepared CPs (a) without clay and (b) with clay at different time intervals.

\section{Sorption kinetics}

Effect of contact time

The copper ion uptake CIU by the prepared CPs $(0.3 \mathrm{~g})$ at natural $(\mathrm{pH} 5.8)$ and at different time intervals is shown in Fig. 8. It is clearly seen from the figure that fast CIU is fixed in the rise and fall sequentially, we find that the highest percentage of them were withdrawn at $40 \mathrm{~min}$ for $\mathrm{CP}$ without and with clay, respectively. This is identical with the results of the water absorption for both CPs. It is clearly seen from the data that the maximum sorption capacities for $\mathrm{Cu}^{+2}$ ions were $200.7 \mathrm{mg} / \mathrm{g}$ and $200 \mathrm{mg} / \mathrm{g} \mathrm{mg} / \mathrm{g}$ for $\mathrm{CP}$ with and without clay, respectively.

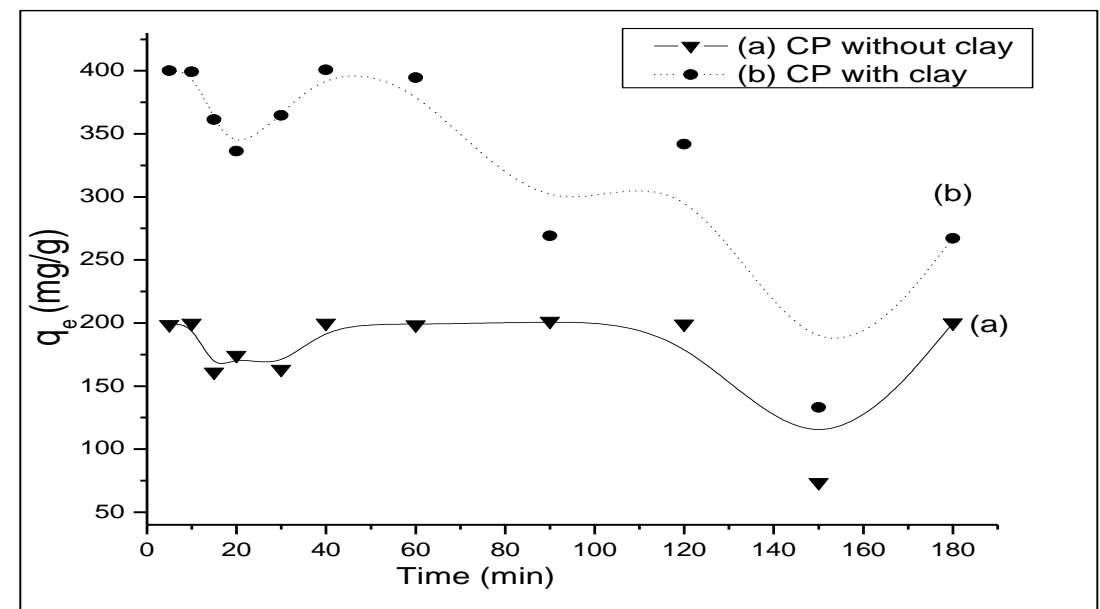

Fig. 8. Sorption of $\mathrm{Cu}^{+2}$ ions by the prepared $\mathrm{CPs}$ (a) without clay and (b) with clay at different time intervals. 
Kinetics of $\mathrm{Cu}(\mathrm{II})$ sorption

The kinetics of $\mathrm{Cu}^{+2}$ ion sorption can be demonstrated using two basic kinetic models including pseudo-first and pseudosecond order. The pseudo-firstorder model is expressed by Lagergren $(1898)^{(31)}$ as:

$$
\log \left(\mathrm{q}_{\mathrm{e}} \mathrm{q}_{\mathrm{t}}\right)=\log \mathrm{q}_{\mathrm{e}_{-}} \mathrm{K}_{1} \mathrm{t} / 2.3
$$

where $\mathrm{k}_{1}$ is the pseudo-first-order rate constant $\left(\mathrm{min}^{-1}\right)$ of adsorption and qe and qt $(\mathrm{mmol} / \mathrm{g})$ are the amounts of metal ion adsorbed at equilibrium and time $\mathrm{t}$ (min), respectively. On the other hand, the pseudo-second order model is expressed by Ho and Mckay ${ }^{(32)}$ as:

$$
\mathrm{t} / \mathrm{qt}=1 / \mathrm{K}_{2} \mathrm{q}_{\mathrm{e}}+\mathrm{t} / \mathrm{q}
$$

where $\mathrm{k}_{2}$ is the pseudo-second-order rate constant of adsorption. The abovementioned two models basically considering external film diffusion, intraparticle diffusion and interaction step for adsorption process. The rate determining step of adsorption reaction may be one of the above three steps (Donia et al., 2008) ${ }^{(33)}$.

The kinetic parameters for the pseudo-first and pseudo-second models were determined from the linear plots of $\log (\mathrm{qe}-\mathrm{qt}$ ) versus $\mathrm{t}$ and (t/qt) versus $\mathrm{t}$, respectively as shown in Fig. $9 \& 10$ and Table 1 . The validity of each model could be checked by the fitness of the straight lines according to the values of correlation coefficients ( $\mathrm{R}^{2}$ values).

It is clearly seen from the figures and correlation coefficient values that the sorption of $\mathrm{Cu}^{+2}$ ions by the prepared $\mathrm{CP}$ in presence and absence of clay fit well pseudo-second-order model. And this indicated that the sorption of $\mathrm{Cu}^{+2}$ ions depends on both the concentration of $\mathrm{Cu}^{+2}$ ions and adsorbent.

TABLE 1. The kinetic parameters for pseudo-first-order and pseudo-second-order

\begin{tabular}{|c|c|c|c|c|}
\hline \multirow{2}{*}{ Sample } & \multicolumn{2}{|c|}{ First Order } & \multicolumn{2}{|c|}{ Second Order } \\
\hline & $\mathbf{K}_{1}$ & $\mathbf{R}^{2}$ & $\mathbf{K}_{2}$ & $\mathbf{R}^{2}$ \\
\hline $\mathrm{CP}$ without clay & 0.0262 & 0.8007 & $9.65 \times 10^{-3}$ & 0.8133 \\
\hline $\mathrm{CP}$ with clay & $7.4038 \times 10^{-4}$ & 0.02769 & $9.329 \times 10^{-3}$ & 0.94358 \\
\hline
\end{tabular}
models .

Egypt. J. Chem. 59, No. 2 (2016) 


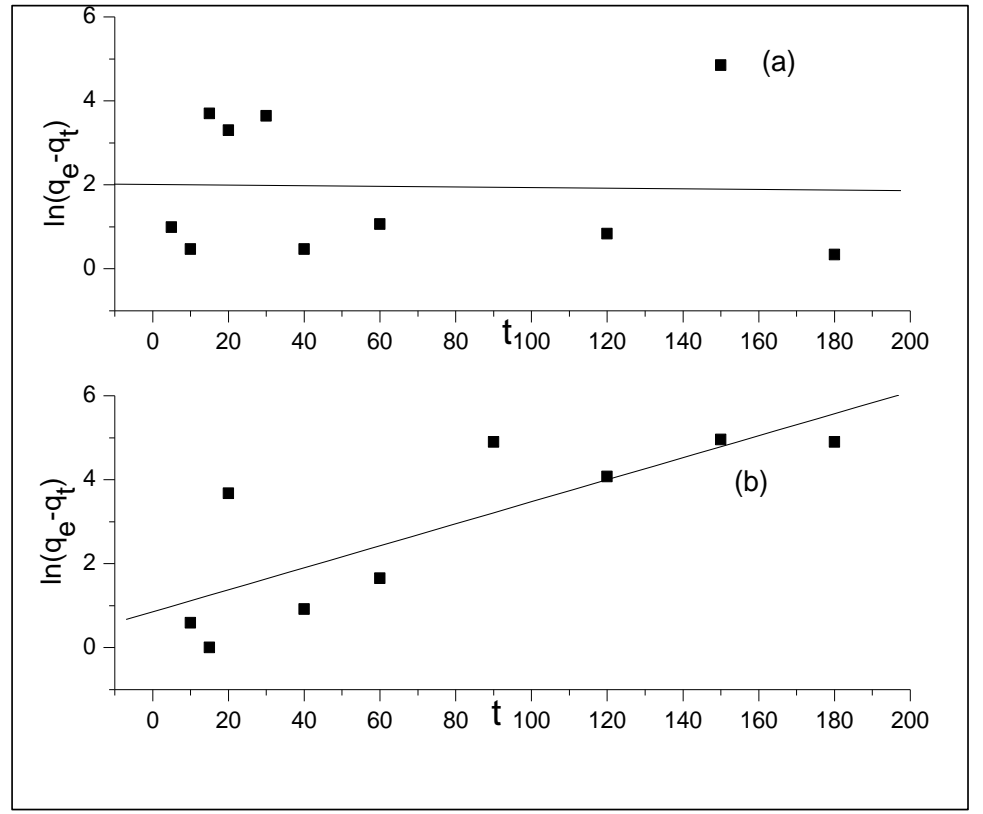

Fig. 9. The First order plots for (a) CP without clay and (b) with clay.

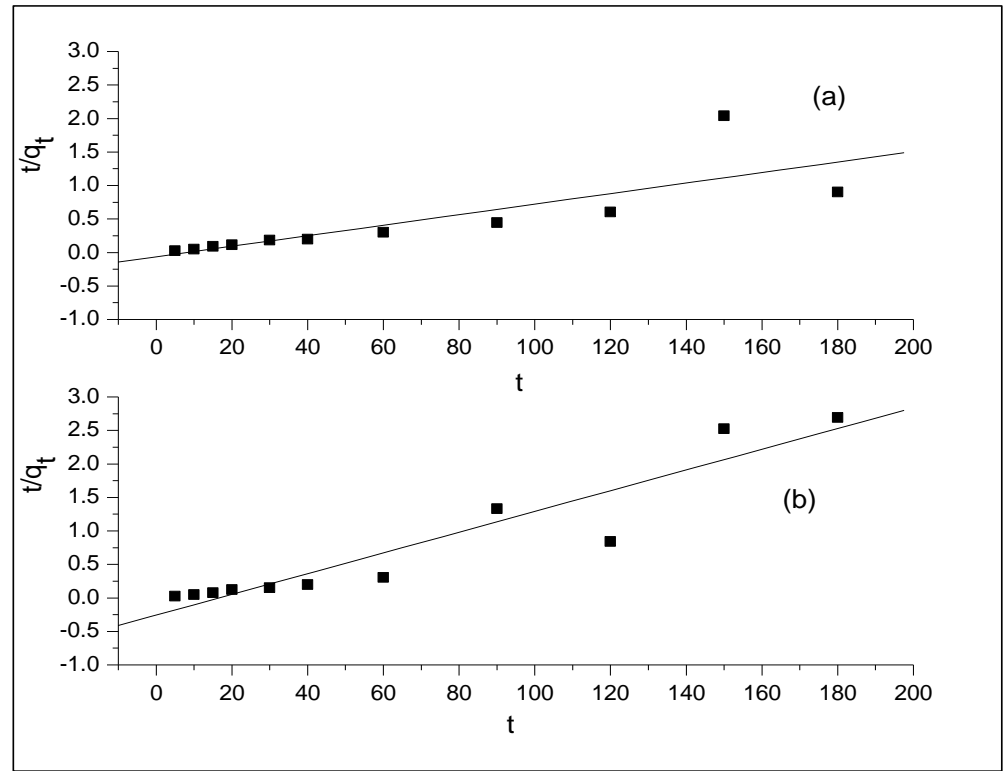

Fig.10. The Second order plots for (a) CP without clay and (b) with clay.

Egypt. J. Chem. 59, No.2 (2016) 


\section{Adsorption isotherms}

Equilibrium data, commonly known as adsorption isotherms, are crucial necessities for the design of adsorption systems. These data give information on the capacity of the adsorbent or the amount necessary to eliminate a unit mass of pollutant under the system conditions $(34,35)$.

In order to adjust the design of a sorption system to remove pollutants from effluents, it is important to set up the most proper correlation for the equilibrium curve. Two isotherm equations have been tested in the current study, namely, Langmuir and Freundlich. This modelling allows us to define the maximum capacity of removal. The quality of the isotherm to fit the experimental data is normally verified according to the value of the correlation coefficient $\left(\mathrm{R}^{2}\right)$, i.e. the isotherm giving $\mathrm{R}^{2}$ value closest to unity is considered to provide the best fit.

Langmuir isotherm : The Langmuir adsorption model assumes that the molecules are adsorbed at fixed number of definite sites, each of which can only hold one molecule and no transfer of adsorbate in plane of the surface. These sites are also supposed to be energetically equivalent and far away from each other, so that there are no interactions between the molecules adsorbed to neighboring sites. The linear form of the Langmuir isotherm is represented by the following equation ${ }^{(36)}$.

$$
\mathrm{C}_{\mathrm{e}} / \mathrm{q}_{\mathrm{e}}=\mathrm{C}_{\mathrm{e}} / \mathrm{Q}_{\max }+1 / \mathrm{Q}_{\max } \mathrm{K}
$$

where $\mathrm{q}_{\mathrm{e}}$ is the amount of metal ion sorbed per unit weight of adsorbent $(\mathrm{mg} / \mathrm{g}), \mathrm{C}_{\mathrm{e}}$ the equilibrium concentration of the metal ion in the equilibrium solution $(\mathrm{mg} / \mathrm{l}), \mathrm{Q}_{\max }(\mathrm{mg} / \mathrm{g})$ is the monolayer adsorption capacity and $\mathrm{K}$ $(\mathrm{L} / \mathrm{mg})$ is Langmuir constant that related to the adsorption heat energy. The results obtained from the Langmuir model for CIU by the prepared CPs are shown in Table 2 and Fig. 11. The values of maximum monolayer capacity $\mathrm{Q}_{\max }$ obtained from Langmuir isotherm indicate that the $\mathrm{CP}$ with clay has higher sorption capacity than that of clay free.

Freundlich isotherm: Freundlich isotherm is an empirical equation that involves the heterogeneity, the exponential distribution of sites, and their energies. The sorption data have been analyzed using the logarithmic form of the Freundlich isotherm as shown below ${ }^{(37)}$ :

$$
\log \mathrm{q}_{\mathrm{e}}=\mathrm{N} \log \mathrm{C}_{\mathrm{e}}+\log \mathrm{K}_{\mathrm{f}}
$$

where $\mathrm{K}_{\mathrm{f}}(\mathrm{mg} / \mathrm{L})$ and $\mathrm{N}$ are Freundlich constants related to adsorption capacity and adsorption intensity, respectively. The value of term $\mathrm{N}$ in the Freundlich isotherm model shows the nature of isotherm to be unfavorable (N $>1)$, favorable $(0<\mathrm{N}<1)$ or irreversible $(\mathrm{N}=0)$. The results obtained from the

Egypt. J. Chem. 59, No. 2 (2016) 
Freundlich model for CIU by the prepared CPs are shown in Table 2 and Fig. 12. The correlation coefficients values deduced from Freundlich equation showed that the Freundlich model is comparable to the Langmuir model. The $\mathrm{N}$ values reported in Table 2 are lower than 1 indicating that $\mathrm{Cu}^{2+}$ ions sorption by the prepared CPs is favorable.

The correlation coefficients values listed in Table 2 indicated that the $\mathrm{Cu}^{+2}$ ions sorption process matches more with Langmuir adsorption model than that of Freundlich.

TABLE 2. Different adsorption models parameters and coefficients for $\mathrm{Cu}^{2+}$ ions sorption.

\begin{tabular}{|c|c|c|c|c|c|c|}
\hline \multirow[b]{2}{*}{ Sample } & \multicolumn{3}{|c|}{ Langmuir } & \multicolumn{3}{|c|}{ Freundlish } \\
\hline & $\mathbf{Q}_{\max }$ & $\mathbf{K}$ & $\mathbf{R}^{2}$ & $\mathbf{K}_{\mathbf{f}}$ & $\mathbf{N}$ & $\mathbf{R}^{2}$ \\
\hline CP without clay & 74.851 & 0.011848 & 0.97348 & $45.4046 \times 10$ & 0.2014 & 0.83595 \\
\hline $\mathrm{CP}$ with clay & 62.814 & 0.011879 & 0.98073 & $58.9223 \times 10$ & 0.27832 & 0.88889 \\
\hline
\end{tabular}

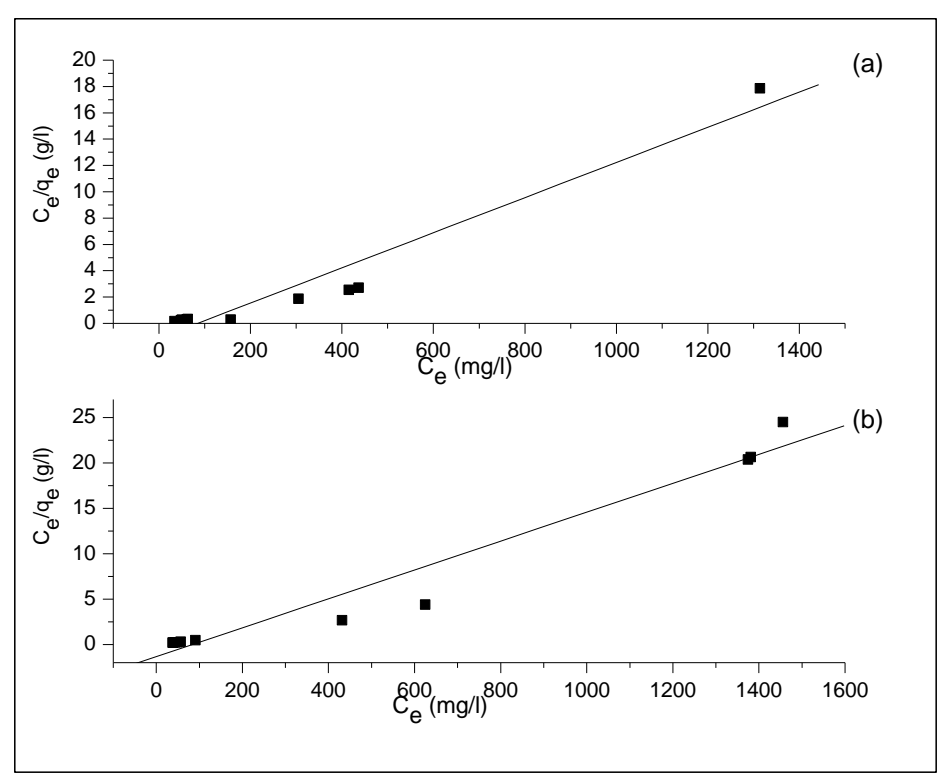

Fig. 11. The Langmuir isotherm plots for (a) CP without clay and (b) CP with clay.

Egypt. J. Chem. 59, No.2 (2016) 


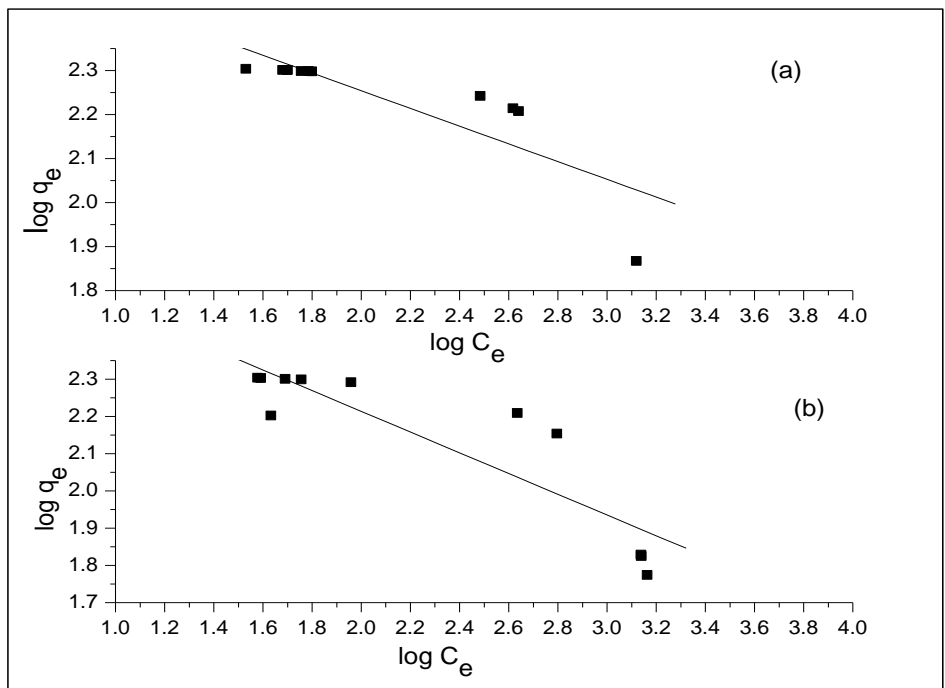

Fig. 12. The Freundlich isotherm plots for (a) CP without clay and (b) CP with clay.

\section{Effect of $p H$}

Figure 13 shows the uptake of $\mathrm{Cu}^{+2}$ ions by the obtained chelating polymers (CPs) at different $\mathrm{pH}$ values. It is shown from the figure that the MIU increases as the $\mathrm{pH}$ increases. At lower $\mathrm{pH}$ value $(1 \& 3)$ the dissociation of the carboxylic acid groups is limited and hence reduces the chelation with different metal ions, but at higher $\mathrm{pH}$ value $(8.5 \& 10)$, ionization of carboxylic acid groups takes place which cause these polymers to undergo a transition from a compact form to an extended form upon the ionization of the primary carboxyl group ${ }^{(38)}$ and hence an increase in the metal ion uptake occurs.

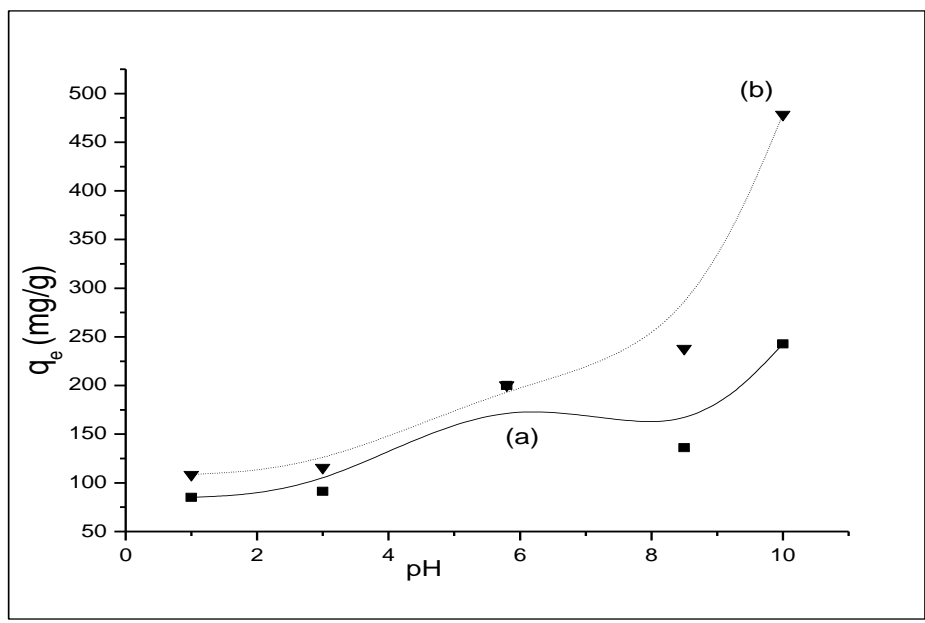

Fig.13. Uptake of $\mathrm{Cu}^{+2}$ by $\mathrm{CP}$ without clay and $\mathrm{CP}$ with clay as a function of $\mathrm{pH}$.

Egypt. J. Chem. 59, No. 2 (2016) 


\section{Selectivity measurements}

Since various metal ion pollutants may present in drinking water as well as wastewater, it is essential to investigate the competitive binding affinity of these ions towards the prepared CPs. The elements constitutions of the tested CPs were detected by the EDAX using a standard less qualitative (EDAX) analytical technique. The peak heights in the EDAX spectra are proportional to the metallic elements concentration which is chemisorbed ${ }^{(39)}$. The EDAX spectrum for $\left(\mathrm{Cr}^{+3}, \mathrm{Co}^{+2}, \mathrm{Ni}^{+2}, \mathrm{Cu}^{+2}, \mathrm{Cd}^{+2}, \mathrm{~Pb}^{+2}\right)$ ions is illustrated in Fig. 14. It could be seen that all previously mentioned metal ions became one element of solid sample in this spectrum and that can be explained as those ions may be chemisorbed on the surface of the CPs as shown in Fig. 15. Elemental constitution is illustrated in Table 3. The sorption capacities of the tested metal ions are in the order $\mathrm{Pb}^{2+}>\mathrm{Cu}^{2+}>\mathrm{Cd}^{2+}>\mathrm{Ni}^{2+}>\mathrm{Co}^{2+}>\mathrm{Cr}^{3+}$; for $\mathrm{CP}$ with clay and in the order $\mathrm{Co}^{2+}>\mathrm{Ni}^{2+}>\mathrm{Pb}^{2+}>\mathrm{Cu}^{2+}>\mathrm{Cd}^{2+}>\mathrm{Cr}^{3+}$ for $\mathrm{CP}$ free of clay as shown in Fig. 16 and Table 3.

TABLE 3. Elemental constitutions (\%) by EDAX analyses.

\begin{tabular}{|c||c|c|c||c||c||c||}
\hline \multirow{2}{*}{ CPs } & \multicolumn{7}{|c|}{ Metal ions Weight \% } \\
& $\mathbf{C r}$ & $\mathbf{C o}$ & $\mathbf{N i}$ & $\mathbf{C u}$ & $\mathbf{C d}$ & $\mathbf{P b}$ \\
\hline \hline Without clay & 7.14 & 27.03 & 22.48 & 16.42 & 8.63 & 18.29 \\
\hline \hline With clay & 0.89 & 1.12 & 4.25 & 8.67 & 6.02 & 84.29 \\
\hline \hline
\end{tabular}

$$
\mathbf{x}
$$

4. EDAX spectrum of grafted waste under: (a) adsorbed without clay; (b) with clay. 


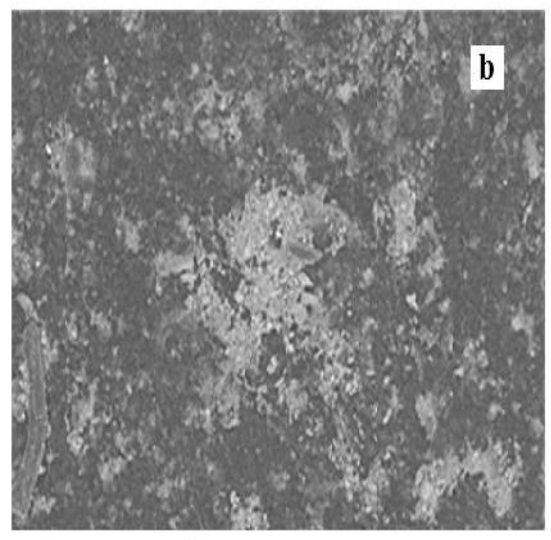

50 um

$1000 \mathrm{X}$

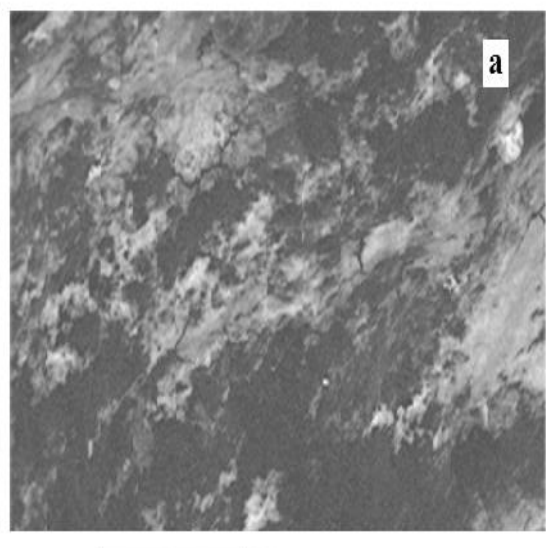

$50 \mu \mathrm{m}$ $1000 \mathrm{X}$

Fig. 15. EDAX for the surface morphology of CPs (a) without clay and (b) with clay.

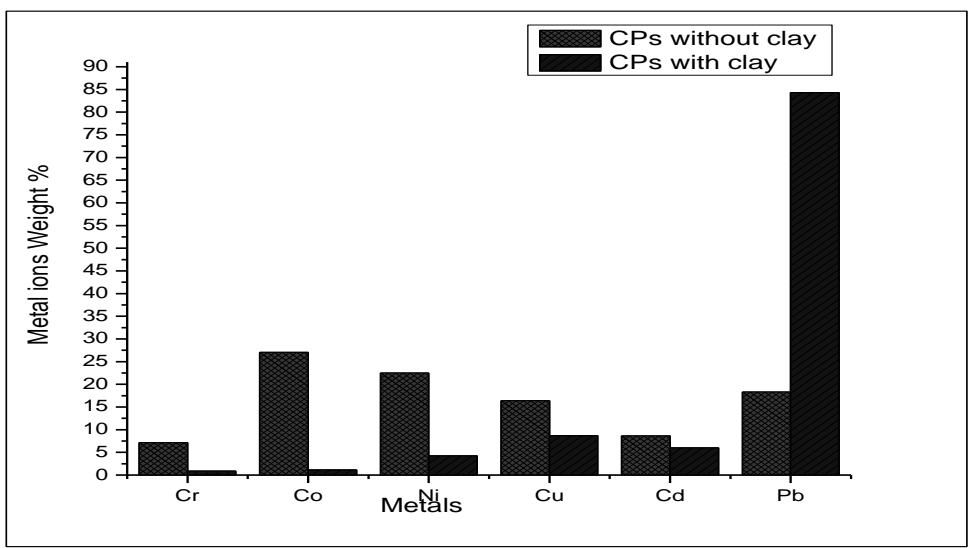

Fig. 16. The competitive binding affinity of the tested metal ions towards the prepared CPs.

Finally, we can conclude that the prepared chelating polymers CPs in this study have given promising results compared to those reported by the traditional chelating resins. The maximum sorption capacity reported in our study for $\mathrm{Cu}^{+2}$ ions is much higher than that reported by Ramazan Cos kun et al. ${ }^{(40)}$, Deniz Türkmen et al. ${ }^{(41)}$, Jinnan Wang et al. ${ }^{(42)}$, Fei Ji et al. ${ }^{\overline{(43)}}$ and Hyonggoo Yoo and Seung-Yeop Kwak ${ }^{(44)}$ as shown from Table 4. In addition, the maximum sorption capacity for the studied metal ion is highly increased at elevated $\mathrm{pH}$ values.

Egypt. J. Chem. 59, No. 2 (2016) 
TABLE 4. Sorption capacity of different chelating resins.

\begin{tabular}{|c|c|c|}
\hline Chelating polymers & Sorption capacity & References \\
\hline $\mathrm{CP}$ without clay & $200 \mathrm{mg} / \mathrm{g}$ & Present study \\
\hline CP with clay & $200.7 \mathrm{mg} / \mathrm{g}$ & Present study \\
\hline $\begin{array}{l}\text { methacrylic acid/acrylamide monomer } \\
\text { mixture grafted poly(ethylene } \\
\text { terephthalate) fiber }\end{array}$ & $31.25 \mathrm{mg} / \mathrm{g}$ & $\begin{array}{l}\text { Ramazan Cos_kun } \\
\quad \text { et al. } 2006\end{array}$ \\
\hline Poly(hydroxyethyl methacrylate) & $58 \mathrm{mg} / \mathrm{g}$ & $\begin{array}{l}\text { Deniz Türkmen } \text { et al. } \\
2009\end{array}$ \\
\hline $\begin{array}{l}\text { hyper-crosslinked } \\
\text { polystyrene }\end{array}$ & $75 \mathrm{mg} / \mathrm{g}$ & $\begin{array}{c}\text { Jinnan Wang et al } \\
2011\end{array}$ \\
\hline $\begin{array}{l}\text { Cellulose acetate }(\mathrm{CA}) / \text { zeolite } \quad(\mathrm{Z}) \\
\text { composite fiber }\end{array}$ & $28.57 \mathrm{mg} / \mathrm{g}$ & Fei Ji et al. 2012 \\
\hline $\begin{array}{l}\text { hyperbranchedpoly(amidoamine)- } \\
\text { graftedpoly(tetrafluoroethylene) }\end{array}$ & $14.2 \mathrm{mg} / \mathrm{L}$ & $\begin{array}{l}\text { Hyonggoo Yoo and } \\
\text { Seung-Yeop Kwak } \\
2013\end{array}$ \\
\hline
\end{tabular}

\section{Conclusion}

In this study a new easily prepared, low-cost and efficient chelating polymers CPs based on waste polymethylmethacrylate plastics have been used as potential adsorbents for removal of toxic heavy metal pollutants from water system. The adsorptions of $\mathrm{Cu}^{2+}$ ions were found to be time dependent. Adsorption isotherms have been studied in terms of Langmuir and Freundlish isotherms models. The values of correlation coefficients deduced from the aforementioned two models confirmed that $\mathrm{Cu}^{+2}$ ions sorption followed Langmuir adsorption model. The selectivity measurements for different toxic heavy metal ions have been investigated and it was found that the competitive binding affinity of the tested metal ions are in the order $\mathrm{Pb}^{2+}>\mathrm{Cu}^{2+}>\mathrm{Cd}^{2+}>\mathrm{Ni}^{2+}>\mathrm{CO}^{2+}>\mathrm{Cr}^{3+}$; for $\mathrm{CP}$ with clay and in the order $\mathrm{Co}^{2+}>\mathrm{Ni}^{2+}>\mathrm{Pb}^{2+}>\mathrm{Cu}^{2+}>\mathrm{Cd}^{2+}>\mathrm{Cr}^{3+}$ for $\mathrm{CP}$ free of clay. The metal ion uptake increases with increasing $\mathrm{pH}$ values due to complete ionization of the $\mathrm{COOH}$ groups occurred at higher $\mathrm{pH}$ values.

Finally, we can conclude that this commercial, easily prepared CPs have double positive features in which it helps to get rid of the organic plastic wastes as well as toxic heavy metal pollutants.

\section{References}

1. Jamil, M., Zia, M.S. and Qasim M., Contamination of agro-ecosystem and human health hazards from waste water used for irrigation. J. Chem. Soc. Pak. 32, 370378(2010). 
2. Khan, S., Cao, Q., Zheng, Y.M., Huang, Zhu, Y.Z. and Y.G., Health risks of heavy metals in contaminated soils and food crops irrigated with wastewater in Beijing, China. Environ. Pollut. 152 686-692 (2008).

3. Singh, A., Sharma, R.K., Agrawal, M. and Marshal, F.M., Health risk assessment of heavy metals via dietary intake of foodstuffs from the wastewater irrigated site of a dry tropical area of India. Food Chem. Toxicol. 48, 611-619(2010).

4. Peng, S.H., Wang, W.X., Li, X.D. and Yen, Y.F., Metal partitioning in river sediments measured by sequential extraction and biomimetic approaches. Chemosphere, 57, 839-851(2004).

5. Fu, F.L. and Wang, Q., Removal of heavy metal ions from wastewaters: A review. Journal of Environmental Management Articles, 92, 407-418(2011).

6. Wang, Y.H., Lin, S.H. and Juang, R.S., Removal of heavy metal ions from aqueous solutions using various low-cost adsorbents. J. Hazard. Mater. 102, 291-302 (2003).

7. O'Connell, D.W., Birkinshaw, C. and O'Dwyer, T.F., Heavy metal adsorbents prepared from the modification of cellulose: a review. Bioresour Technol. 99, 67096724(2008).

8. Kurniawan, T.A., Chan, G.Y.S., Lo, W.H. and Babel, S., Physico-chemical treatment techniques for wastewater laden with heavy metals. Chem. Eng. J. 118 8398 (2006).

9. Galil, N. and Rebhun, M., Primary chemical treatment minimizing dependence on bioprocess in small treatment plants. Water Sci. Technol. 22, 203-210(1990).

10. Tangjuank, S., Insuk, N., Tontrakoon, J. and Udeye, V., Adsorption of lead (II) and Cadmium (II) ions from aqueous solutions by adsorption on activated carbon prepared from cashew nut shells. World Academy of Science, Engineering and Technology; 28, 110-116(2009).

11. Cobianco, S., Lezzi, A. and Scotti, R., A spectroscopic study of $\mathrm{Cu}(\mathrm{II})$-complexes of chelating resins containing nitrogen and sulfur atoms in the chelating groups, 43 7-16 (2000).

12. Gonzalez, MEL. and Arribas, LVP., Chemically modifi ed polymeric sorbents for sample preconcentration. J. Chromatogr A 902, 3-16(2000).

13. Zhou, L., Wang, Y., Liu, Z. and Huang, Q., Characteristics of equilibrium, kinetics studies for adsorption of $\mathrm{Hg}(\mathrm{II}), \mathrm{Cu}(\mathrm{II})$ and $\mathrm{Ni}(\mathrm{II})$ ions by thiourea-modified magnetic chitosan microspheres. J. Hazard. Mater. 161, 995 (2009).

14. Zhou, Y.T., Nie, H.L., White, C.B., He, Z.Y. and Zhu, L.M., Removal of $\mathrm{Cu} 2+$ from aqueous solution by chitosan-coated magnetic nanoparticles modified with alpha-ketoglutaric acid. J. Colloid Interface Sci, 330, 29(2009).

15. Liu, C., Bai, R. and Hong, L., Diethylenetriamine-grafted poly (glycidyl methacrylate) adsorbent for effective copper ion adsorption. J. Colloid Interface Sci. 303, 99(2006).

Egypt. J. Chem. 59, No. 2 (2016) 
16. Liu, C., Bai, R. and Ly, Q.S., Selective removal of copper and lead ions by diethylenetriamine-functionalized adsorbent: Behaviors and mechanisms. Water Res. 42, 1511(2008).

17. Liu, X., Hu, Q., Fang, Z., Zhang, X. and Zhang, B., Magnetic chitosan nanocomposites: a useful recyclable tool for heavy metal ion removal. Langmuir, 25, 3(2009).

18. Pekel, N., Sahiner and N., Guven, O., Use of amidoximated acrylonitrile/N- vinyl 2- pyrrolidone interpenetrating polymer networks for uranyl ion adsorption from aqueous systems. J. Appl. Polym. Sci. 81 (10) 2324(2001).

19. Kasxgoz, H., Durmusx, A. and Kasxgoz, A., Enhanced swelling and adsorption properties of AAm-AMPSNa/clay hydrogel nanocomposites for heavy metal ion removal. Polym. Adv. Technol. 19, 213-220(2008).

20. Sahiner, N., In situ metal particle preparation in cross-linked poly(2-acrylamido-2methyl-1-propansulfonic acid) hydrogel network. Colloid Polym. Sci. 285, 283(2006).

21. Elhalawany, N.R, Haroun, A.A., Abbas, H. A. and Hammad, F. F., Conducting chelating polymer composites based on grafted waste polystyrene for removal of toxic copper ions. Journal of Elastomers and Plastics, 46(6), 553-568(2014).

22. Anirudhan, T.S. and Suchithra, P.S., Heavy metals uptake from aqueous solutions and industrial wastewaters by humic acid-immobilized polymer/bentonite composite: Kinetics and equilibrium modeling. Chemical Engineering Journal, 156 146-156 (2010).

23. Atta, A.M., Al-Lohedan, H.A., ALOthman, Z.A., Abdel-Khalek, A.A. and Tawfeek, A.M., Characterization of reactive amphiphilic montmorillonite nanogels and its application for removal of toxic cationic dye and heavy metals water pollutants. Journal of Industrial and Engineering Chemistry, 31 (2015) 374-384.

24. Liu, J., Ma, Y., Xu, T. and Shao, G., Preparation of zwitterionic hybrid polymer and its application for the removal of heavy metal ions from water. J. Hazard. Mater. 178, 1021-1029(2010).

25. Pan, B., Qiu, H., Pan, B., Nie, G., Xiao, L., Lv, L., Zhang, W., Zhang, Q. and Zheng, S., Highly efficient removal of heavy metals by polymer-supported nanosized hydrated Fe(III) oxides: Behavior and XPS study. Water Res. 44, 815-824. (2010).

26. Ge, F., Li, M., Ye, H. and Zhao, B., Effective removal of heavy metal ions $\mathrm{Cd} 2+$, $\mathrm{Zn} 2+, \mathrm{Pb} 2+, \mathrm{Cu} 2+$ from aqueous solution by polymer-modified magnetic nanoparticles. J. Hazard. Mater. 211-212, 366-372(2012).

27. Iesan, C.M., Capat, C., Ruta, F. and Udrea, I., Characterization of hybrid inorganic/organic polymer-type materials used for arsenic removal from drinking water. React. Funct. Polym. 68, 1578-1586(2008). 
28. Liu, J.S., Ma, Y., Xu, T.W. and Shao, G.Q., Preparation of zwitterionic hybrid polymer and its application for the removal of heavy metal ions from water. J. Hazard. Mater. 178, 1021-1029(2010).

29. Dong, Q., Liu, J.S., Song and L., Shao, G., Novel zwitterionic inorganic-organic hybrids: Synthesis of hybrid adsorbents and their applications for $\mathrm{Cu} 2+$ removal. $J$. Hazard. Mater. 186 ,1335-1342 (2011).

30. Balamurugan, A., Kannan, S., Selvaraj, V. and Rajeswara, S., Development and spectral characterization of poly(methyl methacrylate) /hydroxyapatite composite for biomedical applications artif. Organs, 18, 41-45(2004).

31. Lagergren, S., About the theory of so-called adsorption of soluble substances, Kungliga Svenska Vetenskapsa-Kademiens. Handlingar, 24(4) 1-39(1898).

32. Ho, Y.S., Review of second-order models for adsorption systems. J. Hazard Mater. 136, 681(2006)

33. Donia, A.M., Asem, A.A. and Elwakeel, K.Z., Selective separation of mercury(II) using magnetic chitosan resin modified with Schiff's base derived from thiourea and glutaraldehyde. J. Hazard Mater. 151 372-379 (2003).

34. Özacar, M., Equilibrium and kinetic modelling of adsorption of phosphorus on calcined alunite. Adsorption, 9, 125-132(2003).

35. Özacar, M., Adsorption of phosphate from aqueous solution onto alunite. Chemosphere, 51, 321-327(2003).

36. Unlu, N. and Ersoz, M., Adsorption characteristics of heavy metal ions onto a low cost biopolymeric sorbent from aqueous solutions. J. Hazard Mater. 136, 272(2006)

37. Peric, J., Trrgo, M. and Medvidovic N.V., Removal of zinc, copper and lead by natural zeolite - a comparison of adsorption isotherms. Water Res.38,1839(2004).

38. Tuncer, C.A. and Recat, I.N. and Cengizo, Z.R., Radiation synthesis and uranyl-ion adsorption of poly(2-hydroxyethyl methacrylate/maleic acid) hydrogels. J. Polym Sci. A 39, 277-283(2001).

39. Runping, H., Weihua, Z., Zongpei, Z., Jie, S. and Jiujun, Y., Copper(II) and lead(II) removal from aqueous solution in fixed-bed columns by manganese oxide coated zeolite. Journal of Hazardous Materials, B137 934-942(2006).

40. Ramazan, C.K., Cengiz, S. and Mehmet, S., Removal of some heavy metal ions from aqueous solution by adsorption using poly(ethylene terephthalate)-g-itaconic acid/acrylamide fiber. Reactive \& Functional Polymers, 66, 599-608 (2006).

41. Türkmen, D., Yılmaz, E., Öztürk, N., Akgöl, S. and Denizli, A., Poly (hydroxyethyl methacrylate) nanobeads containing imidazole groups for removal of $\mathrm{Cu}$ (II) ions. Materials Science and Engineering, C 29, 2072-2078 (2009).

Egypt. J. Chem. 59, No. 2 (2016) 
42. Wang, J., Xu, L., Meng, Y., Cheng, C. and Li, A., Adsorption of $\mathrm{Cu}^{2+}$ on new hyper-crosslinked polystyrene adsorbent: batch and column studies. Chemical Engineering Journal, 178, 108-114(2011).

43. Ji, F., Li, C., Tang, B., Xu, J., Lu, G. and Liu, P., Preparation of cellulose acetate/zeolite composite fiber and its adsorption behavior for heavy metal ions in aqueous solution. Chemical Engineering Journal, 209, 325-333(2012).

44. Yoo, H. and Seung-Yeop, K., Surface functionalization of PTFE membranes with hyperbranched poly (amidoamine) for the removal of $\mathrm{Cu} 2+$ ions from aqueous solution. Journal of Membrane Science, 448,125-134 (2013).

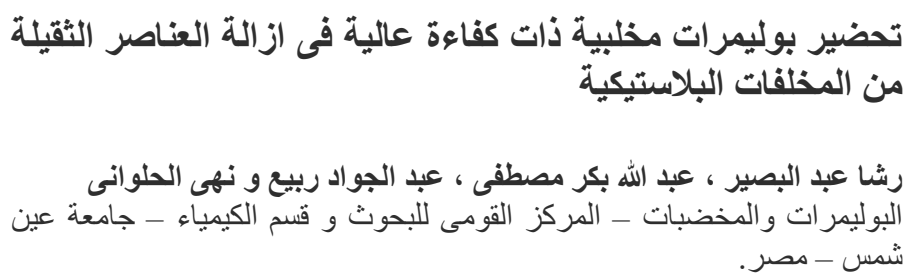

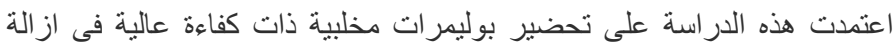

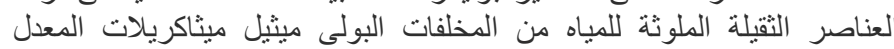

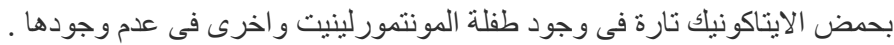

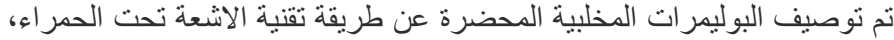

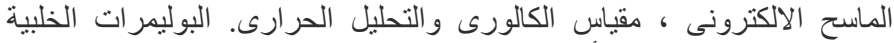

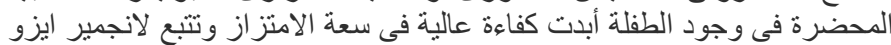

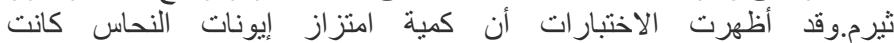

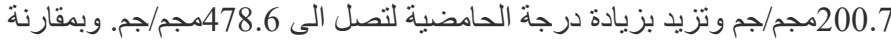

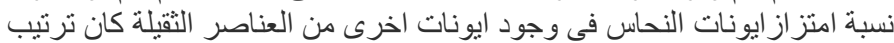

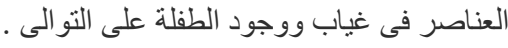

$\mathrm{Co}>\mathrm{Ni}>\mathrm{Pb}>\mathrm{Cu}>\mathrm{Cd}>\mathrm{Cr}$ and $\mathrm{Pb}>\mathrm{Cu}>\mathrm{Cd}>\mathrm{Ni}>\mathrm{Co}>\mathrm{Cr}$ 